\title{
SELF-EXERCISING DEVICE FOR PREVENTION AND TREATMENT OF DROP FOOT
}

\author{
By Herbert H. Shey, M.D. \\ Spinal Cord Injury Service of the Veterans Administration Hospital, Long Beach, California
}

THE development of drop foot remains a problem, especially with bed-confined paraplegic and quadriplegic patients, although the usual measures for prevention may be carried out conscientiously. These include use of boards at the foot of the bed, standing exercises and passive exercises administered by the physiotherapist. It is estimated that on this service (capacity 205 patients) approximately $4 \frac{1}{2}$ hours a week are spent by the physiotherapist in this latter effort on paraplegic patients, and an even greater amount of time on quadriplegic patients.

It was felt that paraplegic patients may be able to utilise the unimpaired functions of their upper extremities to assume this portion of physiotherapy, namely dorsiflexion of the feet. For the purpose of facilitating this aim, the device here presented has been constructed and has been found to be effective. It consists of the following (fig. I);

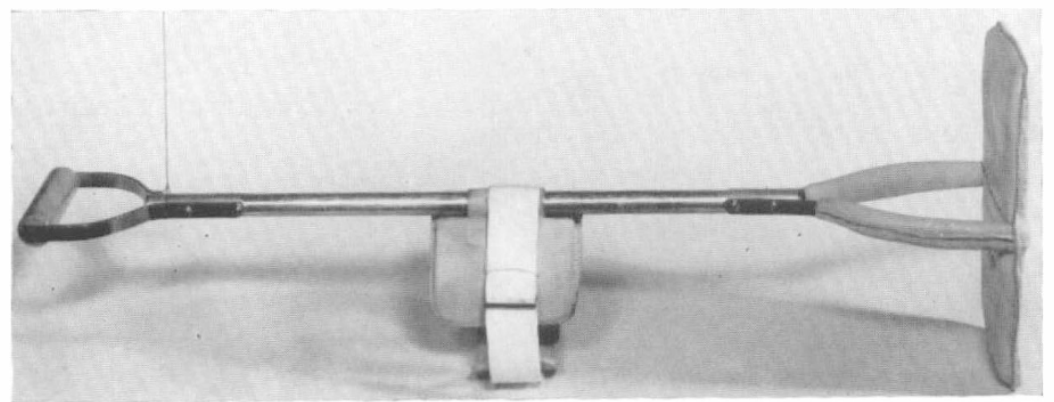

Fig. I

Self-exercising drop foot device.

I. Centre Rod; $\frac{1}{2}$ in. thick, 22 in. long (may be made adjustable).

2. Stirrup; padded prongs, 6 in. long (with extension for attachment to rod, 2 in.); and foot plate, padded, 6 in. wide, ro in. long.

3. Knee Pad; padded, quarter-circle, $4 \frac{1}{2}$ in. wide, 7 in. circumference with attached 2 in. long sleeve to slide on rod; and adjustable belt with padded counter pad.

4. Handle: with sides 4 in. long (with $2 \frac{1}{2}$ in. extension for fixations on rod) and wooden bar I in. thick. 
The device is used in the following manner (fig. 2 and 3 ); the patient slips his foot through the stirrup and attaches the cuff to the knee (fig. 2). He then brings the foot from the 'drop' position to a rectangular one or as close to $90^{\circ}$ as possible (fig. 3). This exercise can be repeated 20 to 30 times, and several times a day.

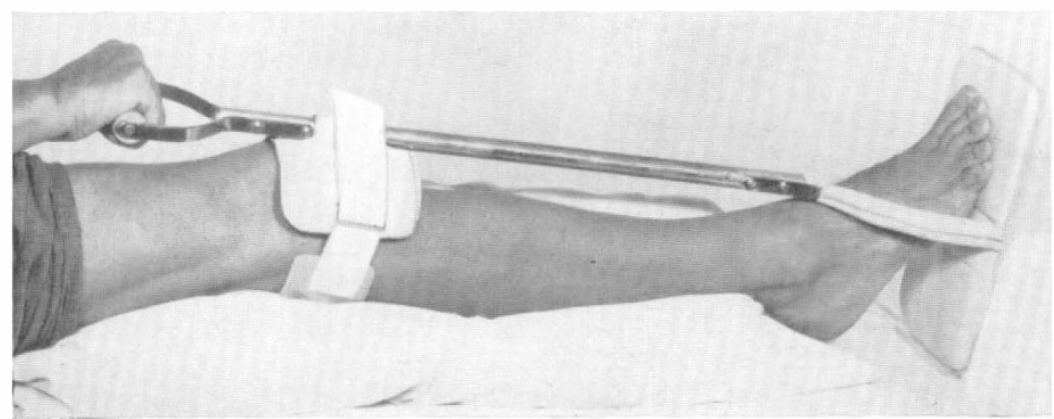

FIG. 2

Device in initial position.

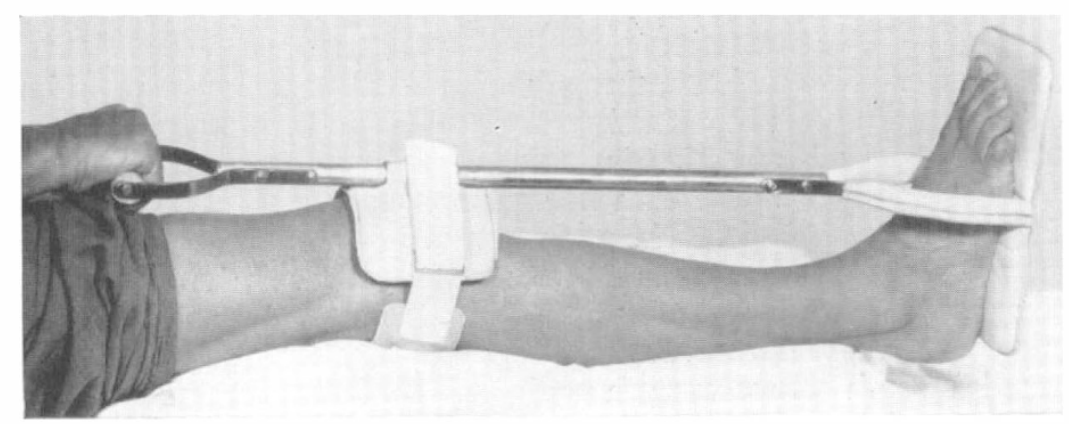

FIG. 3

Device in action position.

This device has been found useful in preventing drop foot and in correcting it where no permanent fixation has occurred. It is easy to manufacture at low cost. In addition to the mechanical benefits obtained by its use, it also presents psychological advantages by allowing the patients to observe their own progress, achieved by their own efforts. 